\title{
O FUTURO PASSADO DO CONSTITUCIONALISMO BRASILEIRO
}

\section{THE PAST FUTURE OF BRAZILIAN CONSTITUTIONALISM}

\author{
Nelson Camatta MOREIRA \\ Pós-doutorado em Direito (Universidad de Sevilla), com bolsa da CAPES. \\ Professor do Programa de Pós-graduação Stricto Sensu (Doutorado e Mestrado) e da Graduação em Direito da \\ Faculdade de Direito de Vitória (FDV-ES). \\ nelsoncmoreira@hotmail.com \\ RODRIGO FRANCISCO DE PAULA \\ Doutorando e mestre em Direito pela Faculdade de Direito de Vitória (FDV-ES). \\ Professor da Graduação em Direito da FDV-ES. Procurador do Estado do Espírito Santo. Advogado.
}

rfdepaula@gmail.com

\begin{abstract}
RESUMO
Neste artigo, analisa-se criticamente a possível relação que se estabelece entre as experiências políticas e constitucionais do Brasil e a expectativa que se abre a partir daí, que limitam - e ao mesmo tempo possibilitam - o horizonte de expectativa acerca do futuro do constitucionalismo brasileiro. Para tanto, trabalha-se com a teoria da história de Reinhart Koselleck, na caracterização da percepção do tempo histórico na época moderna, segundo as categorias meta-históricas do espaço de experiência e do horizonte de expectativa, juntamente com as preocupações de Paul Ricœur sobre os desafios da hermenêutica histórica, como uma mediação constituída por perspectivas cruzadas entre a expectativa do futuro, a recepção do passado e a vivência do presente. Em síntese, sustenta-se que o futuro do constitucionalismo brasileiro precisa assumir uma relação de tensão com o seu passado, na instância mediadora do presente onde se situa a Constituição de 1988, que se abre em direção tanto ao passado quanto ao futuro, no projeto de constituição de um Estado Democrático de Direito no Brasil.
\end{abstract}

Palavras-chave: Constitucionalismo brasileiro; Filosofia crítica; História do Direito.

\begin{abstract}
In this paper, it is critically analyzed the possible relationship between the political and constitutional experiences of Brazil and the expectation that opens from there, limiting - as well making possible - the expectation horizon of the future of Brazilian constitutionalism. Therefore, it is worked with Reinhart Koselleck's theory of history on characterization of the perception of historical time in the modern age, according to the meta-historical categories of space of experience and horizon of expectation, and with Paul Ricœur concerns about the challenges of historical hermeneutics, as a mediation consists of crossed perspectives between the expectation of the future, past reception and the experience of present. In summary, it is argued that the future of Brazilian constitutionalism must assume a tension relationship with its past, in mediating body where is the Constitution of 1988, which opens toward both the past and the future, the project the establishment of a democratic Rule of Law in Brazil.
\end{abstract}

Keywords: Brazilian constitutionalism; Critical philosophy; Law History 


\section{SUMÁRIO}

INTRODUÇAO; 1 A PERCEPÇÃO DO TEMPO HISTÓRICO NA ÉPOCA MODERNA; 2 ENTRE A EXPERIÊNCIA E A EXPECTATIVA DO CONSTITUCIONALISMO BRASILEIRO; CONCLUSÃO; REFERÊNCIAS.

\section{INTRODUÇÃO}

As esperanças depositadas no constitucionalismo brasileiro, com a promulgação da Constituição de 1988, apelidada de "Constituição Cidadã", cedo se frustraram, pelo menos para parte expressiva da doutrina do Direito Constitucional no Brasil.

Pouco mais de 10 anos da promulgação da Constituição de 1988, Fabio Konder Comparato escreveu um réquiem para o texto constitucional, dando como morto o projeto constituinte brasileiro. ${ }^{1}$

Essa postura sobre o passado do constitucionalismo brasileiro reflete a percepção da história constitucional brasileira como a história de uma tragédia do constitucionalismo brasileiro, tal como contada por Paulo Bonavides e Paes de Andrade, por nunca ter sido superada a contradição entre a constitucionalidade formal e a constitucionalidade material. ${ }^{2}$

Trata-se do que Marcelo Andrade Cattoni de Oliveira e David Francisco Lopes Gomes chamam de um elogio ao ressentimento, presente nessas narrativas sobre a história do constitucionalismo brasileiro. ${ }^{3} \mathrm{O}$ que se pretende discutir aqui, então, é de que maneira esse modo de se compreender a história do constitucionalismo brasileiro afeta o sentido atual da Constituição de 1988 e o próprio futuro do constitucionalismo brasileiro.

Em outras palavras, o que se pretende fazer é uma análise dessa possível relação que se estabelece entre as experiências políticas e constitucionais do Brasil e a expectativa que se abre a partir daí, que limitam - e ao mesmo tempo possibilitam - o horizonte de expectativa acerca do futuro do constitucionalismo brasileiro.

\footnotetext{
${ }^{1}$ COMPARATO, Fabio Konder. Réquiem para uma Constituição. In: FIOCCA, Demian; GRAU, Eros Robero (org.). Debate sobre a Constituição de 1988. São Paulo: Paz e Terra, 200,. p. 77.

2 BONAVIDES, Paulo; ANDRADE, Paes. História constitucional do Brasil. 3. ed. Rio de Janeiro: Paz e Terra, 2001, p. 09-12.

${ }^{3}$ CATTONI DE OLIVEIRA, Marcelo Andrade; GOMES, David Francisco Lopes. Independência ou sorte: ensaio de história constitucional do Brasil. Revista da Faculdade de Direito - UFPR, Curitiba, n. 55, p. 19-37, 2012, p. 22-27.
} 


\section{A PERCEPÇÃO DO TEMPO HISTÓRICO NA ÉPOCA MODERNA}

Reinhart Koselleck, ao estabelecer a relação entre passado e futuro na história moderna, cria noção de "futuro passado dos tempos modernos", ${ }^{4}$ esclarecendo que a modernização do conceito de história se dá, exatamente, com a temporalização da história, com uma forma peculiar de aceleração, em que, na instância mediadora do presente, passado e futuro se encontram na constituição do tempo histórico. ${ }^{5}$

A aceleração do tempo histórico se torna uma categoria pós-cristã e histórico-temporal na medida em que “(...) a doutrina dos dois reinos é substituída pela história e pelo tempo histórico, agora invocado e mobilizado como última instância de justificação para os planejamentos políticos e a organização social". ${ }^{6}$

Essa transformação da estrutura temporal se dá gradativamente, a partir da segunda metade do século XVII, com a consciência assumida de que o homem havia passado a viver na modernidade “(...) estando ao mesmo tempo consciente de estar vivendo nela". 7

Um novo e inédito tipo de futuro se abre a partir daí, estruturado em termos do prognóstico racional, como momento consciente de ação política, em substituição às antigas profecias, que confinavam as previsões do futuro à escatologia cristã, concentrada no apocalipse. Acentua Koselleck que “(...) o tempo passa a derivar, então, do próprio prognóstico, de uma maneira continuada e imprevisivelmente previsível”. ${ }^{8}$

Com isso, o prognóstico torna-se instrumento por excelência da política, com a transformação do futuro profetizado em futuro prognosticável, tendo por fio condutor o progresso, colocado no futuro, com a possibilidade de se ultrapassar o espaço do tempo e da própria experiência, provocando novos prognósticos, transnaturais e de longo prazo. ${ }^{9}$

Torna-se possível, então, na modernidade, um planejamento temporal do futuro que podia se descolar do espaço de experiência, abreviado no tempo presente sob a perspectiva da

\footnotetext{
${ }^{4}$ KOSELLECK, Reinhart. Futuro passado: contribuição à semântica dos tempos históricos. Trad. Wilma Patrícia Maas e Carlos Almeida Pereira. Rio de Janeiro: Contraponto/PUC-Rio, 2006. p. 21.

${ }_{6}^{5}$ Ibid., p. 23.

${ }^{6}$ Ibid., p. 171.

${ }^{7}$ Ibid., p. 31.

${ }^{8}$ Ibid., p. 32.

${ }^{9}$ Ibid., p. 35-36.
} 
aceleração do tempo histórico, muito embora daí surja um movimento de adiamento, contribuindo para a antecipação do tempo histórico pela alternância entre reação e revolução. ${ }^{10}$

Nesse sentido, o conceito de história passa a ter de “(...) servir para cobrir todas as extensões temporais - desde a expectativa de futuro, sem base na experiência, até a pesquisa sobre o passado, destituída de qualquer expectativa". ${ }^{11}$

Para Koselleck, espaço de experiência e horizonte de expectativa, como categorias meta-históricas que decodificam a história, servem para estabelecer as condições das histórias possíveis, não as histórias mesmas, sendo capazes de fundamentar a possibilidade de uma história. ${ }^{12}$ Por isso,

[...] experiência e expectativa são duas categorias adequadas para nos ocuparmos com o tempo histórico, pois elas entrelaçam passado e futuro. São adequadas também para se tentar descobrir o tempo histórico, pois, enriquecidas em seu conteúdo, elas dirigem as ações concretas no movimento social e político. ${ }^{13}$

Enquanto a experiência é o passado atual, a expectativa é o futuro atual, que se encontram, portanto, na atualidade do presente, sem guardar entre si uma relação simétrica complementar, já que não são imagens especulativas recíprocas.

Há uma relação de tensão entre experiência e expectativa, porque passado e futuro jamais coincidem, uma expectativa jamais pode ser deduzida totalmente da experiência, assim como a experiência futura, antecipada como expectativa, decompõe-se em uma infinidade de momentos temporais. ${ }^{14}$ Pontua Koselleck: “(...) a presença do passado é diferente da presença do futuro". ${ }^{15}$

Há um aprendizado com o tempo, com a reunião de novas experiências, que abrem perspectivas diferentes e novas expectativas, que se voltam para as experiências e reconfiguram o tempo histórico: “(...) portanto, também as experiências já adquiridas podem modificar-se com o tempo". ${ }^{16}$

\footnotetext{
${ }^{10}$ KOSELLECK, Reinhart. Futuro passado: contribuição à semântica dos tempos históricos. Trad. Wilma Patrícia Maas e Carlos Almeida Pereira. Rio de Janeiro: Contraponto/PUC-Rio, 2006, p. 36-37.

${ }^{11}$ KOSELLECK, Reinhart; MEIER, Christian; GÜNTHER, Horst; ENGELS, Odilo. O conceito de história. Trad. René E. Gertz. Belo Horizonte: Autêntica, 2013, p. 207.

12 KOSELLECK, Reinhart. Futuro passado: contribuição à semântica dos tempos históricos. Trad. Wilma Patrícia Maas e Carlos Almeida Pereira. Rio de Janeiro: Contraponto/PUC-Rio, 2006, p. 306.

${ }^{13}$ Ibid., p. 308.

${ }^{14}$ Ibid., p. 309-310.

${ }^{15}$ Ibid., p. 311.

${ }^{16}$ Ibid., p. 312.
} 
Assim, é da tensão entre experiência e expectativa que se pode deduzir o tempo histórico, de uma forma sempre diferente, porque novas soluções podem ser suscitadas a partir da própria estrutura temporal dessas categorias.

Enquanto a experiência só pode surgir de uma expectativa retroativa, a expectativa não pode ser adquirida sem experiência, embora não se esgote nela, dada a sua abertura para o futuro. Diz Koselleck: “(...) as experiências se superpõem, se impregnam uma das outras. E mais: novas esperanças ou decepções retroagem, novas expectativas abrem brechas e repercutem nelas". ${ }^{17}$

E quando a expectativa é superada, há um ganho de experiência, que rompe o horizonte de expectativa, ultrapassando a então limitação do futuro possível. Daí a conclusão: “(...) visto dessa maneira, o que estende o horizonte de expectativa é o espaço de experiência aberto para o futuro. As experiências liberam os prognósticos e os orientam". ${ }^{18}$

Esse modo de se compreender o tempo histórico, na época moderna, é constitutivo do modo de se fazer (ou se contar) a história que surge a partir daí, influenciando de modo decisivo as narrativas históricas.

Ter consciência disso é indispensável para compreender qualquer narrativa histórica, ou melhor, suas potencialidades no que diz respeito à relação estabelecida entre a experiência do passado (espaço de experiência) e a expectativa do futuro (horizonte de expectativa).

É nesse contexto que pode ser inserida a obra de Paul Ricœur, mais especificamente, sua hermenêutica da consciência histórica. Para ele, uma vez abandonada a ideia de mediação total para se pensar a história e o tempo da história, como pretendeu Hegel, resta a via da “(...) mediação aberta, inacabada, imperfeita”, constituída por “(...) uma rede de perspectivas cruzadas entre a expectativa do futuro, a recepção do passado, a vivência do presente, sem Aufhebung numa totalidade em que a razão da história e sua efetividade coincidiriam". ${ }^{19}$

Daí surge a proposta de uma hermenêutica da consciência histórica, na qual o serafetado-pelo-passado, no espaço comum de experiência, constitui o presente histórico. ${ }^{20}$

De um lado, Ricœur parte da dialética do triplo presente de Santo Agostinho, que coloca o passado e o futuro no presente, articulando memória (passado), atenção (presente) e expectativa (futuro), reduzindo a extensão do tempo à distensão da alma, porque "ele vê a

${ }^{17}$ KOSELLECK, Reinhart. Futuro passado: contribuição à semântica dos tempos históricos. Trad. Wilma Patrícia Maas e Carlos Almeida Pereira. Rio de Janeiro: Contraponto/PUC-Rio, 2006, p. 313.

${ }^{18}$ Ibid., p. 313.

${ }^{19}$ RICOEUR, Paul. Temps et récit. Paris: Éditions du Seuil, 1985b. T. 3: Le temps raconté, p. 374.

${ }^{20}$ Ibid., p. 421. 
discordância nascer e renascer da própria concordância das visadas da expectativa, da atenção e da memória". ${ }^{21}$

De outro lado, Ricœur busca os fundamentos da narrativa histórica na intriga poética (o par mímesis-mŷthos), que consiste no agenciamento dos fatos, no sentido de que "a imitação ou a representação é uma atividade mimética na medida em que produz algo, ou seja, precisamente o agenciamento dos fatos pela composição da intriga". ${ }^{22}$

Daí a hipótese levantada, no sentido de que “(...) o tempo torna-se tempo humano na medida em que está articulado de modo narrativo, e a narrativa alcança sua significação plenária quando se torna uma condição da existência temporal". ${ }^{23}$

Assim, “(...) é tarefa da hermenêutica reconstruir o conjunto das operações pelas quais uma obra se destaca do fundo opaco do viver, do agir e do sofrer, para ser dada por um autor a um leitor que a recebe e assim muda seu agir". ${ }^{24}$

Isso porque é possível estabelecer uma relação entre a teoria narrativa e a teoria da ação, ou seja, entre narrar e agir, o que se dá por meio da pressuposição e da transformação, na medida em que toda narrativa pressupõe uma familiaridade do auditório com os termos utilizados pelo narrador, mas não se limita a isso, porque traz consigo também aspectos discursivos, que compõem a ordem sintagmática que confere um caráter diacrônico à história narrada. ${ }^{25}$

Assim, a interpretação, na operação historiográfica, deve se realizar em quatro perspectivas: (i) na preocupação em tornar claro para o interlocutor o que está sendo narrado, facilitando-lhe a compreensão; (ii) na clareza de que sempre é possível interpretar de outro modo o que está sendo narrado, reconhecendo-se um grau inevitável de controvérsia entre as interpretações possíveis do que ocorreu; (iii) na pretensão de se dotar a própria intepretação com argumentos plausíveis; (iv) na confissão de que por trás de qualquer interpretação sempre jazem motivações pessoais e culturais irrenunciáveis (RICOEUR, 2000, p. 442). ${ }^{26}$

Assim, tanto a narrativa historiográfica, quanto a própria hermenêutica - que tem nela e na narrativa histórica o seu campo de trabalho -, devem ser encaradas segundo as seguintes premissas: (i) o passado não é algo estático, com significado unívoco do qual possa ser extraída a

${ }^{21}$ RICCEUR, Paul. Temps et récit. Paris: Éditions du Seuil, 1985a. T. 1: L'intrigue et le récit historique, p. 49.

${ }^{22}$ Ibid., p. 72.

${ }^{23}$ Ibid., p. 105.

${ }^{24}$ Ibid., p. 106-107.

${ }^{25}$ Ibid., p. 111-112.

${ }^{26}$ Ibid., p. 442. 
história; o passado é aquilo que aparece na memória e desaparece no esquecimento, sendo objeto da narrativa histórica; (ii) é tarefa da hermenêutica desvendar, de um ponto de vista crítico, a história que subjaz à memória, resgatando do esquecimento os rastros deixados que foram ignorados (ou mesmo manipulados) na narrativa histórica.

Essa rápida descrição da teoria da história de Koselleck, juntamente com as preocupações de Ricœur sobre os desafios da hermenêutica histórica, permite uma análise crítica da história do constitucionalismo brasileiro, tal como vem sendo contada.

\section{ENTRE A EXPERIÊNCIA E A EXPECTATIVA DO CONSTITUCIONALISMO BRASILEIRO}

No caso do constitucionalismo brasileiro, ainda existem poucas obras que se dedicam a recuperar o passado constitucional do Brasil em uma narrativa histórica estruturada segundo a percepção do tempo histórico na época moderna. Ou, pelo menos, não se encontram esforços no sentido de se relacionar o passado com o presente, tampouco com o futuro, do constitucionalismo brasileiro.

Paulo Bonavides e Paes de Andrade escreveram, pouco tempo após a promulgação da Constituição de 1988, uma obra dedicada a contar a história constitucional do Brasil que ainda hoje é referência no assunto. ${ }^{27}$

Mas já de partida, eles esclarecem que “(...) tem essa história um fundamento elitista porque o provo não a escreveu”, uma vez que o verdadeiro poder soberano do povo “(...) só tem aparecido em ocasiões raras, de sorte que seu exercício político imediato fica frequentemente coartado pela intermediação e infidelidade de governantes habituados ao poder sem freios e sem limitações". ${ }^{28}$

Daí a afirmação categórica de que "o problema constitucional do Brasil, como se vê, passa por uma enorme contradição entre a constitucionalidade formal e a constitucionalidade material".29

De fato, todos os períodos constitucionais do Brasil, desde a Constituição de 1824 até a Constituição de 1988, são narrados sob essa perspectiva de irremediável fracasso. E mesmo

27 BONAVIDES, Paulo; ANDRADE, Paes. História constitucional do Brasil. 3. ed. Rio de Janeiro: Paz e Terra, 2001.

28 Ibid., p. 05.

29 Ibid., p. 09. 
excluindo-se os dois períodos ditatoriais, inaugurados em 1937, com Getúlio Vargas, e em 1964, com as Forças Armadas - cujo fracasso do constitucionalismo seria mais evidente -, não são encontradas experiências dignas de nota em cada tempo histórico constituído por cada uma das Constituições brasileiras.

Isso porque, na história constitucional do Brasil assim contada, o desencontro entre a constitucionalidade formal e a constitucionalidade material estaria sempre caracterizado, seja porque a outorga da Constituição de 1824 “(...) se desvanecia então à sombra de um poder absoluto e impopular (...)"; ${ }^{30}$ seja porque a Constituição de 1891 não guardava correspondência com a realidade, de modo que “(...) até mesmo as formas mais puras da construção liberal cedo se esclerosaram"; ${ }^{31}$ seja, ainda, porque o texto da Constituição de 1934 é marcado por indecisões e ambiguidades, pelo que “(...) não é possível delinear a partir dele um projeto político hegemônico para o país”; 32 seja, por fim, porque a Constituição de 1946 “(...) não logrou fazer-se presente no dia-a-dia do povo, nem mesmo demonstrar que era instrumento de participação e mudança". ${ }^{33}$

Até mesmo o processo constituinte que deu origem à Constituição de 1988, embora seja apontado como o mais legítimo que o país já teve, não escapa de críticas quanto à sua legitimidade, porque a assembleia constituinte foi convocada pelos próprios poderes constituídos da ordem constitucional anterior, o que comprometeria, decisivamente, a sua autonomia para dispor com legitimidade sobre a nova ordem, muito embora se aponte que a ação participativa popular teria legitimado a constituinte. ${ }^{34}$

Assim, o passado do constitucionalismo brasileiro ganha, geralmente, o aspecto de uma imagem fixa em que a experiência política e constitucional do Brasil se apresenta marcada indelevelmente pelos traços da ilegitimidade, sempre conduzida pela dominação de uma elite de visão estreita, da falta de efetividade das sucessivas Constituições, desprovidas do reconhecimento de sua força normativa e da falta de vontade política de se lhes dar aplicabilidade, e do desrespeito à legalidade constitucional, diante do reiterado desprezo à normatividade constitucional, como anotam Luís Roberto Barroso e Ana Paula de Barcellos. ${ }^{35}$

\footnotetext{
30 BONAVIDES, Paulo; ANDRADE, Paes. História constitucional do Brasil. 3. ed. Rio de Janeiro: Paz e Terra, 2001, p. 80.

31 Ibid., p. 249.

32 Ibid., p. 320.

33 Ibid., p. 410.

34 Ibid., p. 489-492.

35 BARROSO, Luís Roberto; BARCELLOS, Ana Paula de. O começo da história. A nova interpretação constitucional e o papel dos princípios no direito brasileiro. In: BARROSO, Luís Roberto (org.). A nova
} 
Deposita-se, assim, na Constituição de 1988 e, por conseguinte, na interpretação que se faz das normas constitucionais no presente, o ônus de se impor sobre uma tradição desprezível, tendo surgido daí a proposta de uma nova interpretação constitucional, calcada na valorização da normatividade dos princípios, na ponderação de valores constitucionais e na teoria da argumentação jurídica. ${ }^{36}$

A questão que se coloca é se essa desvalorização do passado pode efetivamente contribuir para o projeto de constituição de um Estado Democrático de Direito no Brasil, ignorando a historicidade do texto constitucional atualmente em vigor, cuja origem deita raízes em algum lugar do passado do constitucionalismo brasileiro.

Há dois problemas que podem ser aí desvelados; (i) a impossibilidade de se descontextualizar historicamente a Constituição de 1988 das tensões que nela subsistem em decorrência do passado do constitucionalismo brasileiro; (ii) a impossibilidade de se compreender o presente e o futuro do constitucionalismo brasileiro sem se levar a sério o seu passado.

Por um lado, é possivel invocar uma das teses de François Ost acerca da relação entre tempo e direito, ao defender que a função principal do jurídico é contribuir para a instituição do social. Ou seja, “(...) o direito é um discurso performativo, um tecido de ficções operatórias que exprimem o sentido e o valor da vida em sociedade". ${ }^{37}$

Essa relação se dá de modo paradigmático no momento da fundação da ordem jurídica, que se expressa no poder constituinte e coloca em questão a relação da nova ordem com a ordem anterior.

Para Ost, há uma relação dialética entre o tempo instituinte e o tempo instituído, na medida em que “(...) não existe força instituinte que não se apoie em formas instituídas”. 38

A fundação não se dá em um golpe de direito, como se fosse possível, na leitura de Jacques Derrida, “(...) um acto de rejeição de qualquer anterioridade e de pura afirmação de si”. ${ }^{39}$ Com Paul Ricœur, Ost propõe interpretar de outra forma a retirada do fundamento da

interpretação constitucional: ponderação, direitos fundamentais e relações privadas. Rio de Janeiro: Renovar, 2003, p. 327-329.

36 BARROSO, Luís Roberto; BARCELLOS, Ana Paula de. O começo da história. A nova interpretação constitucional e o papel dos princípios no direito brasileiro. In: BARROSO, Luís Roberto (org.). A nova interpretação constitucional: ponderação, direitos fundamentais e relações privadas. Rio de Janeiro: Renovar, 2003, p. 330-337.

${ }^{37}$ OST, François. 0 tempo do direito. Trad. Maria Fernanda Oliveira. Lisboa: Piaget, 1999, p. 13-14.

${ }^{38}$ Ibid., p. 77.

${ }^{39}$ Ibid., p. 73. 
fundação, para nela encontrar “(...) não um vazio e um desmame, mas pelo contrário um elo que não pára de se estender e de se enriquecer em direcção a um passado que nunca deixou de irradiar em direcção ao presente". ${ }^{40}$

É na preservação dessa dialética entre o tempo instituinte e tempo instituído que se desenvolve a questão da legitimidade do direito, onde vai se dar, como em uma instância mediadora, o equilíbrio entre a força instituída e a força instituinte.

Nesse sentido, voltando-se para a história do constitucionalismo brasileiro como vem sendo contada, não se pode pretender atribuir à Constituição de 1988 o começo da história constitucional brasileira, relegando todo o seu passado a um campo obscuro designado de préhistória constitucional brasileira, como fazem Luís Roberto Barroso e Ana Paula de Barcellos, ao denunciarem a ilegitimidade, a falta de efetividade das sucessivas Constituições, e o desrespeito à legalidade constitucional, como o único legado possível do passado constitucional. ${ }^{41}$

Efetivamente, o passado constitucional continua a irradiar seus efeitos sobre o presente e desvendar esses efeitos é tarefa que se impõe na interpretação das normas constitucionais, sob pena de se frustrar o próprio projeto constituinte (re)inaugurado pela Constituição de 1988.

Por outro lado, aprofundando-se essa relação entre o passado e o presente do constitucionalismo, com reflexos para o seu futuro, é possível afirmar, com Gustavo Zagrebelsky, que a história constitucional é “(...) a contínua reelaboração das raízes constitucionais do ordenamento que nos é imposta no presente pelas exigências constitucionais do futuro". ${ }^{42}$

A dimensão histórica do direito constitucional não pode, portanto, ser jamais desconsiderada, senão com o risco de se comprometer o próprio sentido das normas constitucionais no presente e reduzir o alcance de suas potencialidades no que condiz com a tarefa que a própria Constituição se impõe de constituir uma nova ordem.

Jürgen Habermas, a propósito, sustenta que “(...) todas as gerações posteriores enfrentarão a tarefa de atualizar a substância normativa inesgotável do sistema de direitos

\footnotetext{
${ }^{40}$ OST, François. 0 tempo do direito. Trad. Maria Fernanda Oliveira. Lisboa: Piaget, 1999, p. 74.

41 BARROSO, Luís Roberto; BARCELLOS, Ana Paula de. O começo da história. A nova interpretação constitucional e o papel dos princípios no direito brasileiro. In: BARROSO, Luís Roberto (org.). A nova interpretação constitucional: ponderação, direitos fundamentais e relações privadas. Rio de Janeiro: Renovar, 2003, p. 327-330.

42 ZAGREBELSKY, Gustavo. Historia y constitución. Trad. Miguel Carbonell. Madrid: Editorial Trotta, 2005, p. 91.
} 
estatuído no documento da constituição”, desde que esse processo possa ser “(...) interpretado, a longo prazo, como um processo de aprendizagem que se corrige a si mesmo". ${ }^{43}$

Falta, portanto, à história do constitucionalismo brasileiro, reconfigurar o campo das experiências políticas e constitucionais vivenciadas no país, levando-se a sério o seu passado para buscar extrair o significado de tais experiências no tempo histórico constituído por cada uma das Constituições brasileiras.

Com isso, quer-se afirmar que não se pode contar a história do constitucionalismo sob uma perspectiva, falsamente crítica, de um irremediável fracasso, porque

não aceitando as tensões entre sucessos e fracassos, entre avanços e retrocessos, entre aberturas e fechamentos hermenêuticos, essa crítica joga por terra quaisquer experiências em termos de democracia, república, igualdade e liberdade construídas, ainda que precariamente e numa dimensão contrafática, no transcorrer da história do Brasil. ${ }^{44}$

Mais do que isso, desse novo espaço de experiência que se abre emerge um novo horizonte de expectativa, pela descoberta de novos acontecimentos passados que se dão a conhecer (o passado atual), em um processo de contínua reelaboração, que traz um novo sentido, no tempo presente, sobre os limites e possibilidades do projeto constituinte brasileiro (o futuro atual).

Colocada a história do constitucionalismo brasileiro sob essa visada, conclui-se que a linha de continuidade não se apaga diante das sucessivas Constituições que sobrevieram no decurso do tempo histórico. Desde que tudo começou no Brasil, em termos de projeto constituinte, com a fundação de um Estado de Direito através da Constituição de 1824, foram-se lhe acrescendo novos acontecimentos que podem ser entendidos como pontos de reflexão sobre a história que vinha se fazendo e que se pretendia fazer.

Embora o surgimento de uma nova Constituição, como ato de fundação que é, coloque em questão sua relação com as experiências do passado, daí não se segue que a Constituição necessariamente rejeite toda a experiência política e constitucional que the é anterior, sobretudo se a Constituição "nova" também se inserir, ainda que sob uma renovada perspectiva, em um projeto constituinte de um Estado de Direito.

43 HABERMAS, Jürgen. O Estado democrático de direito - uma amarração paradoxal de principios contraditórios? In: HABERMAS, Jürgen. Era das transições. Trad. Flávio Beno Siebeneichler. Rio de Janeiro: Tempo Brasileiro, 2003, p. 165.

${ }^{44}$ CATTONI DE OLIVEIRA, Marcelo Andrade; GOMES, David Francisco Lopes. Independência ou sorte: ensaio de história constitucional do Brasil. Revista da Faculdade de Direito - UFPR, Curitiba, n. 55, p. 19-37, 2012, p. 26. 
Tais experiências são criticamente reunidas no mesmo espaço de experiência e se cruzam, na instância mediadora do presente, com o horizonte de expectativa que orienta o momento histórico tanto do ato de fundação (a Constituição, nesse sentido, como princípio) quanto dos atos seguintes que virão a ampliar o projeto constituinte.

Nesse passo, a Constituição “nova”, ao mesmo tempo em que rejeita a Constituição "antiga", é, também, resultado dela, como um ganho de experiência que rompeu o horizonte de expectativa anterior. Assim, as experiências forjadas no passado, com fundamento na "antiga" Constituição, superpõem-se em um mesmo espaço de experiência com as lutas por direitos manifestadas com fundamento na "nova" Constituição, todas elas orientadas pelo projeto constituinte de um Estado de Direito, quando, então, são ressignificadas no tempo presente, à luz do horizonte de expectativa atual que repercute sobre elas.

Portanto, o futuro do constitucionalismo brasileiro depende do significado que se atribui, hoje, ao seu passado. Essa conclusão, longe de ser demasiadamente simples, procura não reduzir a complexidade da tarefa que se impõe de compreender a Constituição de 1988 no tempo histórico por ela inaugurado, sem desconsiderar a tensão entre o passado e o futuro que se manifesta em cada ato de atribuição de sentido às normas constitucionais.

\section{CONCLUSÃO}

Os desafios postos ao projeto constituinte de um Estado Democrático de Direito no Brasil são enormes. Mas tem havido um permanente desperdício da experiência ao longo da história constitucional, pelo menos na visada das narrativas sobre a história do constitucionalismo brasileiro que ainda hoje predominam.

E essa postura influencia, decisivamente, o sentido que se atribui, no presente, às normas constitucionais, ao mesmo tempo em que diz muito, também, sobre o futuro da Constituição de 1988 e do próprio constitucionalismo brasileiro.

Afinal, na percepção do tempo histórico, lembrando-se aqui as considerações de Reinhart Koselleck, o horizonte de expectativa que orienta o futuro se abre a partir do espaço de experiência que decorre do passado, na instância mediadora do presente, de tal modo que se não forem considerados os ganhos de experiência do passado, o futuro será condenado a ser uma repetição dos mesmos fracassos ou, quando menos, será sobrecarregado por prognósticos desorientados. 
Uma controvérsia constitucional que envolva, por exemplo, o sentido dos direitos fundamentais na Constituição de 1988 deve levar em consideração a tensão entre o passado e o futuro do constitucionalismo brasileiro existente no texto constitucional. ${ }^{45}$

Assim, tomando-se por exemplo a liberdade de reunião, tal e qual prevista normativamente no texto constitucional em vigor, com a garantia de que pode ser realizada pacificamente em locais abertos ao público, independentemente de autorização, desde que não frustre outra reunião anteriormente convocada para o mesmo local, sendo apenas exigido prévio aviso à autoridade competente (artigo $5^{\circ}$, inciso XVI, da Constituição de 1988), representa um ganho em relação à experiência constitucional anterior, que previa a liberdade de reunião pacífica, mas admitia que por lei fossem determinados os casos em que era necessária a comunicação prévia à autoridade, bem como a designação, por esta, do local da reunião (artigo 150, § 27, da Constituição de 1967; ${ }^{46}$ artigo 153, § 27, da “Emenda Constitucional” n 01/1969). ${ }^{47}$

Ignorar esse ganho de experiência, conquistado por tantos que foram às ruas protestar contra a ordem autocrática anterior, equivale a limitar o horizonte de expectativa que se abre para o constitucionalismo brasileiro, como se fosse possível encontrar o sentido da Constituição de 1988 fechando-se nela mesma.

Vale dizer, no exemplo citado, o significado da liberdade de reunião, quando colocado em discussão diante de eventual situação concreta onde se discuta o seu sentido e o seu alcance hoje, à luz da Constituição de 1988, não pode prescindir de toda a carga nele contida a partir das experiências que podem ser resgatadas do passado do constitucionalismo brasileiro.

Outros tantos exemplos poderiam ser citados e mesmo experiências ocorridas no tempo histórico de Constituições brasileiras mais longínquas entram, de igual modo, no espaço de experiência sobre o qual se assenta a Constituição de 1988, inserida na história do constitucionalismo brasileiro.

Para ilustrar essa possibilidade, pode ser tomado como outro exemplo a discussão que hoje se estabelece sobre a possibilidade de haver o ingresso forçado em imóveis particulares

\footnotetext{
${ }^{45}$ BRASIL. Constituição da República Federativa do Brasil. Brasília: Senado Federal, 1988. Disponível em: <http://www.planalto.gov.br/ccivil_03/Constituicao/Constituiçao.htm>. Acesso em: 9 jun. 2016. Acesso em: 09 jun. 2016.

${ }^{46}$ BRASIL. Constituição da República Federativa do Brasil. Brasília: Senado Federal, 1967. Disponível em: <http://www.planalto.gov.br/ccivil_03/Constituicao/Constituicao67.htm>. Acesso em: 9 jun. 2016. Acesso em: 09 jun. 2016.

${ }^{47}$ BRASIL. Emenda Constitucional $n^{\circ} 1$ de 17 de outubro de 1969. Brasília: Senado Federal, 1967. Disponível em: <http://www.planalto.gov.br/ccivil_03/Constituicao/Emendas/Emc_anterior1988/emc0169.htm>. Acesso em: 9 jun. 2016. Acesso em: 09 jun. 2016.
} 
para efeito de ser realizado o controle sanitário no interesse da defesa e da proteção da saúde pública.

Essa questão passou a ser considerada diante da situação de iminente perigo à saúde pública pela presença do mosquito transmissor do vírus da dengue, do vírus chikungunya e do zika vírus, o que levou à recente edição da Medida Provisória $n^{\circ} 712 / 16$, prevendo, dentre outras medidas, o ingresso forçado em imóveis públicos e particulares, no caso de situação de abandono ou de ausência de pessoa que possa permitir o acesso de agente público, regularmente designado e identificado, quando se mostre essencial para a contenção das doenças (artigo $1^{\circ}$, § $1^{\circ}$, inciso III)..$^{48}$

Ora, o texto constitucional em vigor garante a inviolabilidade do domicílio, reconhecendo que ninguém pode entrar na casa sem o consentimento do morador, salvo em caso de flagrante delito ou desastre, ou para prestar socorro, ou, durante o dia, por determinação judicial (artigo $5^{\circ}$, inciso XI), ao mesmo tempo que em admite o uso da propriedade particular pela autoridade pública no caso de iminente perigo público, assegurando ao proprietário indenização posterior (artigo $5^{\circ}$, inciso XXV).

Mas a intervenção do Estado na vida privada das pessoas, tendo por objetivo a proteção e a defesa da saúde pública, já levou à deflagração de uma insurreição popular ao tempo histórico da Constituição de 1891. Trata-se da Revolta da Vacina, ocorrida em 1904, quando se colocou em debate público a legitimidade da intervenção estatal na vida privada a partir do plano de regulamentação da aplicação da vacina obrigatória contra a varíola e da determinação de demais providências de caráter sanitário para se enfrentar outras pestes que se alastravam no país no início do século passado (febre amarela, peste bubônica, tifo, tuberculose etc.).

$\mathrm{Na}$ mesma época, as pessoas foram ao Poder Judiciário reclamar a proteção de seus direitos então previstos no texto constitucional, invocando, para tanto, o artigo 72 , § 11, da Constituição de 1891, que previa que somente por lei seria possível prescrever em quais casos seria permitido, de dia, a entrada em casa particular sem consentimento do respectivo morador.

O Supremo Tribunal Federal, ao julgar um habeas corpus impetrado em favor de Manoel Fortunato de Araújo Costa, que houvera recebido pela segunda vez uma intimação para franquear o acesso à sua casa a um inspetor sanitário para que houvesse a desinfecção por

\footnotetext{
48 BRASIL. Medida Provisória $n^{\circ} 712$ de 29 de janeiro de 2016. Dispõe sobre a adoção de medidas de vigilância em saúde quando verificada situação de iminente perigo à saúde pública pela presença do mosquito transmissor do Vírus da Dengue, do Vírus Chikungunya e do Zika Vírus. Diário Oficial da União. Brasília, DF, $1^{\circ}$ fev. 2016. Disponível em: <http://www.planalto.gov.br/CCIVIL_03/_Ato20152018/2016/Mpv/mpv712.htm>. Acesso em: 09 jun. 2016.
} 
motivo de febre amarela, considerou “(...) inconstitucional a disposição regulamentar que faculta à autoridade sanitária penetrar, até com o auxílio da força pública, em casa particular para levar a efeito operações de expurgo". ${ }^{49}$

Essa experiência precisa ser levada em consideração, hoje, na análise da legitimidade da intervenção do Estado na vida privada das pessoas, tendo por objetivo a proteção e a defesa da saúde pública.

E tantos outros exemplos poderiam ser citados. O que se quer evidenciar aqui é a necessidade dessa contínua reelaboração do passado do constitucionalismo brasileiro para se compreender o seu presente e orientar os prognósticos de seu futuro.

É por isso que a aposta de Luís Roberto Barros e Ana Paula de Barcellos de vislumbrarem em uma nova interpretação constitucional, assentada em um modelo cujas possibilidades e limites se esgotam apenas na Constituição de 1988, ao desprezarem o passado constitucional, desconsidera a historicidade em que se encontra mergulhado o texto constitucional, como narrativa onde subjazem, em relação de tensão, os restos do seu passado e as sementes de seu futuro.

Com isso, em tal perspectiva, do mesmo modo que são ignorados os restos do passado constitucional no presente do constitucionalismo brasileiro, são, em igual medida, sufocadas as sementes plantadas no ato de fundação do tempo histórico inaugurado pela Constituição de 1988.

Ora, as experiências vividas hoje, amanhã se tornam passado e acabam entrando nesse mesmo campo de desesperança. Esse tem sido o futuro passado do constitucionalismo brasileiro, levando a um sentimento de frustração que tem o potencial de arrastar todas as experiências sempre para a mesma catástrofe, o que permitiu, por exemplo, Fabio Konder Comparato a enterrar, em pouco tempo, as esperanças depositadas na promulgação da Constituição de 1988.

O papel de uma hermenêutica histórica, aplicada ao constitucionalismo brasileiro, deve ser o questionamento desse passado dado como algo estático, fechado em si mesmo, procurando-se desvendar, de um ponto de vista crítico, a história que subjaz à memória, resgatando do esquecimento os rastros deixados que foram ignorados (ou mesmo manipulados) na narrativa histórica, como acentua Paul Ricœur.

\footnotetext{
${ }^{49}$ BRASIL. Supremo Tribunal Federal. Acórdão de decisão que concedeu a ordem de habeas corpus. Recurso de Habeas Corpus $n^{\circ}$ 2.244. Pedro Tavares Junior e Juiz Seccional da $2^{\text {a }}$ Vara do Distrito Federal. Relator: Ministro Pedro Antonio de Oliveira Ribeiro. 31 de janeiro de 1905. Disponível em: < $\mathrm{http} / / / \mathrm{www}$.stf.jus.br/portal/cms/verTexto.asp?servico=sobreStfConhecaStfJulgamentoHistorico\&pagina= rhc2244>. Acesso em: 11 jun. 2016.
} 
0 futuro do constitucionalismo brasileiro precisa assumir, portanto, essa relação de tensão com o seu passado, na instância mediadora do presente onde se situa a Constituição de 1988, que se abre em direção tanto ao passado quanto ao futuro, no projeto de constituição de um Estado Democrático de Direito no Brasil.

\section{REFERÊNCIAS}

BRASIL. Supremo Tribunal Federal. Acórdão de decisão que concedeu a ordem de habeas corpus. Recurso de Habeas Corpus $n^{\circ} 2.244$. Pedro Tavares Junior e Juiz Seccional da $2^{\text {a }}$ Vara do Distrito Federal. Relator: Ministro Pedro Antonio de Oliveira Ribeiro. 31 de janeiro de 1905. Disponível em: <

http://www.stf.jus.br/portal/cms/verTexto.asp?servico=sobreStfConhecaStfJulgamentoHistoric o\&pagina=rhc2244>. Acesso em: 11 jun. 2016.

BRASIL. Constituição da República Federativa do Brasil. Brasília: Senado Federal, 1988. Disponível em: <http://www.planalto.gov.br/ccivil_03/Constituicao/Constituiçao.htm>. Acesso em: 9 jun. 2016.

BRASIL. Constituição da República Federativa do Brasil. Brasília: Senado Federal, 1967. Disponível em: <http://www.planalto.gov.br/ccivil_03/Constituicao/Constituicao67.htm>. Acesso em: 9 jun. 2016.

BRASIL. Emenda Constitucional $n^{\circ} 1$ de 17 de outubro de 1969. Brasília: Senado Federal, 1967. Disponível em:

<http://www.planalto.gov.br/ccivil_03/Constituicao/Emendas/Emc_anterior1988/emc0169.htm>. Acesso em: 9 jun. 2016.

BRASIL. Medida Provisória ${ }^{\circ} 712$ de 29 de janeiro de 2016. Dispõe sobre a adoção de medidas de vigilância em saúde quando verificada situação de iminente perigo à saúde pública pela presença do mosquito transmissor do Vírus da Dengue, do Vírus Chikungunya e do Zika Vírus. Diário Oficial da União. Brasília, DF, $1^{\circ}$ fev. 2016. Disponível em:

<http://www.planalto.gov.br/CCIVIL_03/_Ato2015-2018/2016/Mpv/mpv712.htm>. Acesso em: 09 jun. 2016.

CATTONI DE OLIVEIRA, Marcelo Andrade; GOMES, David Francisco Lopes. Independência ou sorte: ensaio de história constitucional do Brasil. Revista da Faculdade de Direito - UFPR, Curitiba, n. 55, 2012, p. 19-37.

COMPARATO, Fábio Konder. Réquiem para uma Constituição. In: FIOCCA, Demian; GRAU, Eros Roberto. Debate sobre a Constituição de 1988. São Paulo: Paz e Terra, 2001, p. 77-87.

BARROSO, Luís Roberto; BARCELLOS, Ana Paula de. O começo da história. A nova interpretação constitucional e o papel dos princípios no direito brasileiro. In: BARROSO, Luís Roberto (Org.). A nova interpretação constitucional: ponderação, direitos fundamentais e relações privadas. Rio 
ISSN 1981-3694

(DOI): $10.5902 / 1981369422877$

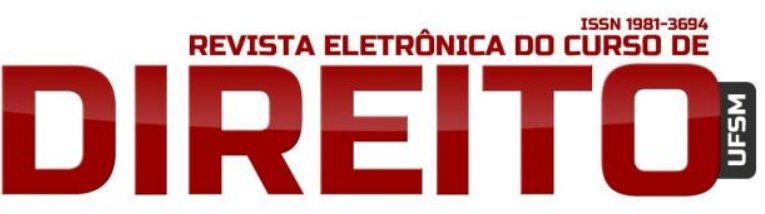

O FUTURO PASSADO DO CONSTITUCIONALISMO BRASILEIRO

Nelson CAMATtA MoReira RODRIGO FRANCISCO DE PAULA

de Janeiro: Renovar, 2003. p. 329-378.

BONAVIDES, Paulo; ANDRADE, Paes de. História constitucional do Brasil. 3. ed. Rio de Janeiro: Paz e Terra, 1991.

HABERMAS, Jürgen. O Estado democrático de direito - uma amarração paradoxal de princípios contraditórios? In: HABERMAS, Jürgen. Era das transições. Trad. Flávio Beno Siebeneichler. Rio de Janeiro: Tempo Brasileiro, 2003. p. 153-173.

KOSELLECK, Reinhart. Futuro passado: contribuição à semântica dos tempos históricos. Trad. Wilma Patrícia Maas e Carlos Almeida Pereira. Rio de Janeiro: Contraponto/PUC-Rio, 2006.

KOSELLECK, Reinhart. Estratos do tempo: estudos sobre história. Trad. Markus Hediger. Rio de Janeiro: Contraponto/PUC-Rio, 2014.

KOSELLECK, Reinhart; MEIER, Christian; GÜNTHER, Horst; ENGEL, Odilo. O conceito de história. Trad. René E. Gertz. Belo Horizonte: Autêntica Editora, 2013.

OST, François. O tempo do direito. Trad. Maria Fernanda Oliveira. Lisboa: Piaget, 1999.

RICOEUR, Paul. Temps et récit. Paris: Éditions du Seuil, 1985a. T. 1: L’intrigue et le récit historique.

RICOEUR, Paul. Temps et récit. Paris: Éditions du Seuil, 1985b. T. 3: Le temps raconté.

ZAGREBELSKY, Gustavo. Historia y constitución. Trad. Miguel Carbonell. Madrid: Editorial Trotta, 2005.

Recebido em: 27/06/2016 / Aprovado em: 17/06/2016 